\title{
EL FOMENTO DE LA “ECONOMÍA SOCIAL” EN LA LEGISLACIÓN ESPAÑOLA ${ }^{1}$
}

\author{
POR \\ Gemma FAJARDO GARCÍA ${ }^{2}$
}

\section{RESUMEN}

La "economía social" como concepto identificativo de una forma de hacer empresa, caracterizada por sus fines y ciertas pautas de comportamiento comunes, ha tenido reconocimiento en la legislación española desde los años 90 y especialmente en el último año con la aprobación de la Ley 5/2011 de Economía Social.

Los objetivos principales de esta Ley son dar reconocimiento legal a la economía social y promover su fomento. Pero la economía social, como identificación de una realidad económica viene siendo objeto de fomento desde mucho antes, desde la creación en 1990 del Instituto Nacional de Fomento de la Economía Social.

Hoy en día, el fomento de la economía social es una competencia asumida por todas las Comunidades Autónomas. Se subvencionan normalmente los gastos derivados de actividades de promoción de la economía social y los gastos generales de funcionamiento de sus entidades representativas. Pero el concepto de economía social utilizado identifica, con alguna excepción (mutualidades y empresas de inserción), exclusivamente a las cooperativas y sociedades laborales. La razón está en que dentro de cada administración pública el fomento de la economía social suele ser competencia de la administración competente en materia de

\footnotetext{
${ }^{1}$ Este trabajo forma parte del proyecto de investigación financiado por el Ministerio de Ciencia e Investigación que lleva por título: La economía social en las políticas públicas. Perspectiva de política económica (DER200914462-C02-02).

${ }^{2}$ Gemma Fajardo García: Profesora Titular Derecho Mercantil, Universidad de Valencia. Dirección de correo electrónico: fajardo@uv.es

REVESCO No 107 - Primer Cuatrimestre 2012 - ISSN: 1885-8031 - www.ucm.es/info/revesco
}

DOI: 10.5209/rev_REVE.2012.v107.38747

Fecha de recepción: 07/07/2011

Fecha de aceptación: 01/09/2011 
empleo. Con la nueva ley, el fomento de la economía social debería alcanzar a todas las demás familias y para ello sería aconsejable que su fomento se atribuyese a un organismo interministerial.

Palabras clave: Subvenciones, Normas, Cooperativas, Tercer Sector, Sociedades Laborales.

Claves ECONLIT: K390, L310, P130

\title{
PROMOTING THE “SOCIAL ECONOMY” IN SPANISH LEGISLATION
}

\begin{abstract}
The "social economy" as a concept identify a way of doing business, characterized by its purposes and certain patterns of behavior common, it has been recognized in Spanish legislation since the 90's and especially in the last year with the approval of Law 5 / 2011 Social Economy.
\end{abstract}

The main objectives of this Act are giving legal recognition to the social economy and promote its development. But the social economy, as identification of an economic reality has been under development long before, since the creation in 1990 of the National Institute for the Promotion of Social Economy.

Nowadays, the promotion of social economy is a responsibility assumed by the Autonomous Communities. It usually subsidize the costs of activities to promote the social economy and general operating expenses of their representative entities. But the concept of social economy used identifies, with some exceptions only to cooperatives and worker-owned companies. The reason is that within each public administration to promote the social economy is generally the responsibility of the competent authority in employment. With the new law, the promotion of social economy should reach all the other families and it would be advisable for their promotion it attributed to an inter-ministerial organism.

Keywords: Subsidies, Standars, Cooperatives, Third Sector, Worker-owed companies. 


\section{INTRODUCCIÓN}

La "economía social" es un concepto presente en la literatura económica desde el primer tercio del siglo XIX ${ }^{3}$. Con esta expresión se ha querido identificar una forma de hacer empresa diferente, caracterizada por una serie de notas que la distinguen de las empresas públicas y de las empresas mercantiles. Esa forma diferente de hacer empresa es la que caracteriza inicialmente a las cooperativas, mutualidades y ciertas asociaciones.

Estas entidades tienen en común su finalidad, que no es lucrativa sino de servicio a sus socios y a la colectividad, y ciertas pautas de comportamiento como son el libre y voluntario acceso a la condición de socio; la gestión democrática de la empresa; la doble condición en sus socios de consumidores o proveedores y propietarios de los medios de producción; la igualdad de derechos y obligaciones de aquellos; el destino de los excedentes al crecimiento de la empresa o a mejorar los servicios a los socios, y por último, la contribución al desarrollo de las comunidades en las que se asientan. Todas estas notas, destacadas en la Carta de la Economía Social suscrita en 1982 por los representantes de las asociaciones, mutualidades y asociaciones francesas ${ }^{4}$, son comunes a las empresas de economía social y a la vez diferenciales de otras formas jurídicas de organización empresarial.

Con el tiempo, el concepto de economía evolucionó para incorporar también a las fundaciones, de esta forma se refuerza en el concepto de economía social, la finalidad de servicio a la colectividad y el destino desinteresado de los beneficios a un patrimonio común; sin embargo, algunas de las notas comunes ya no son aplicables a las fundaciones, todas las que hacen referencia a los socios (libre acceso, gestión democrática, igualdad de derechos de los socios, doble condición ...) ya que la fundación no tiene una base asociativa sino que constituye un patrimonio dotado de personalidad jurídica.

Actualmente, la organización europea representativa de las entidades de economía social, Conferencia Europea Permanente de las Cooperativas, Mutualidades, Asociaciones y

\footnotetext{
${ }^{3}$ Entre las primeras obras suele citarse a DUNOYER, Ch. Nouveau Traité d'économie sociale, Sautelet, Paris (1830).

${ }^{4}$ « Texte de la Charte de l’Economie Sociale» publicado en Revue des études coopératives nº 9, 1983 p. 114.
} 
Fundaciones (denominada desde 2008 Social Economy Europe), identifica como características comunes de estas empresas las siguientes ${ }^{5}$ :

- Prioridad de la persona y del objeto social sobre el capital.

- Adhesión voluntaria y abierta

- Control democrático por sus miembros (a excepción de las fundaciones)

- Conjunción de los intereses de los miembros y del interés general.

- Defensa y aplicación de los principios de solidaridad y responsabilidad.

- Autonomía de la gestión e independencia respecto de los poderes públicos.

- Destino de la mayoría de sus excedentes a la consecución de objetivos a favor del desarrollo sostenible, la mejora de los servicios a los miembros y el interés general.

La economía social, como realidad económica, tiene una larga tradición en las legislaciones europeas así como en la española, las cooperativas, mutualidades, asociaciones o fundaciones, están reconocidas y reguladas en nuestros ordenamientos desde el siglo XIX. Sin embargo, la economía social, como expresión o denominación de esa realidad económica, es mucho más reciente. Posiblemente, sea en Francia donde por vez primera se recoge en la ley la expresión "economía social”. En concreto, en las leyes de 20 de julio no 83-657 y 12 julio $\mathrm{n}^{\circ}$ 85-703 relativas al desarrollo de ciertas actividades de economía social, publicadas respectivamente en 1983 y 1985.

En España, es a partir de 1990 cuando el término economía social comienza a tener reconocimiento en la ley.

\section{DELIMITACIÓN DEL OBJETO DE ESTUDIO}

El objeto que nos proponemos con este trabajo es analizar la presencia de la economía social en la legislación española, como concepto identificativo de una realidad económica, pero limitando nuestro estudio a las normas que el legislador ha dedicado a su fomento.

Por ello haremos en primer lugar una breve referencia al reconocimiento de la "economía social” en las leyes españolas, y posteriormente, analizaremos las normas que

\footnotetext{
5 Estos son los denominados Principios de la Economía Social aprobados en 2002 por las entidades representativas en el ámbito europeo de las empresas de economía social. Véanse en su web http://www.socialeconomy.eu.org/
}

REVESCO No 107 - Primer Cuatrimestre 2012 - ISSN: 1885-8031 - www.ucm.es/info/revesco 
tienen por objeto fomentar la economía social, ello nos dará cuenta no sólo de qué actuaciones se promueven sino también de qué entiende el legislador por economía social en dichas normas.

Este análisis normativo se ha realizado tomando en consideración la legislación española tanto estatal como autonómica. Debe tenerse en cuenta que en nuestro Estado, las Comunidades Autónomas no sólo tienen competencias de fomento de las entidades de economía social, sino también competencias legislativas en muchos casos.

\section{BREVE REFERENCIA AL RECONOCIMIENTO DE LA "ECONOMÍA SOCIAL" EN LA LEGISLACIÓN ESPAÑOLA}

La economía social, como concepto identificativo de una realidad económica, comienza a tener reconocimiento en la legislación española con la Ley de Presupuestos Generales del Estado 31/1990, de 27 de diciembre (art. 98), que crea el Instituto Nacional de Fomento de la Economía Social (INFES), como Organismo Autónomo de carácter administrativo, adscrito al Ministerio de Trabajo y Seguridad Social, sustituyendo a la hasta entonces Dirección General de Cooperativas y Sociedades Laborales.

Este instituto tenía entre sus objetivos, como su mismo nombre sugiere, el fomento de las empresas de economía social. El Real Decreto 1836/1991 que desarrolló esta norma define estas empresas como "aquellas que tengan por objeto la prestación de bienes y servicios a sus asociados, participando éstos directa y democráticamente en la toma de decisiones, y aquéllas en las que los trabajadores ostenten la mayoría del capital social. Asimismo se considerarán incluidas las personas físicas o jurídicas que realicen una actividad socioeconómica mediante cualquier fórmula de autoempleo". "En concreto, componen el concepto de economía social las Cooperativas de cualquier tipo, las Sociedades Anónimas Laborales y cualesquiera otras entidades que reúnan los requisitos o cumplan las condiciones que se establezcan normativamente”.

Las funciones y competencias del Instituto Nacional de Fomento de la Economía Social fueron transferidas en 1997 a la Dirección General de Fomento de la Economía Social 
y del Fondo Social Europeo ${ }^{6}$. La estructura administrativa cambió pero la economía social se mantuvo como área de interés prioritario para la Administración.

La economía social está presente en las instituciones públicas del Estado y de las Comunidades Autónomas, y ha sido objeto desde hace años de diversas políticas públicas de fomento, pero faltaba en nuestro ordenamiento un claro reconocimiento de lo que debía entenderse por economía social, que complementara las diversas alusiones que las normas vienen realizando a esta realidad económica.

La aprobación en 2009 de la Resolución del Parlamento Europeo sobre la Economía Social $^{7}$, pone de manifiesto que a pesar de las ventajas que la economía social reporta al desarrollo de la economía europea ${ }^{8}$, no podrá prosperar si no se dan determinadas condiciones. Para ello, el Parlamento establece una serie de recomendaciones que giran en torno al reconocimiento del concepto de economía social; de los estatutos jurídicos europeos de asociaciones, fundaciones y mutualidades ${ }^{9}$; reconocimiento estadístico de las empresas de economía social y reconocimiento como interlocutor social de los representantes de estas entidades. Entre esas recomendaciones merece citarse a los efectos de nuestro estudio las siguientes:

- Recomendación dirigida a la Comisión para que en sus políticas promueva la economía social y defienda el concepto de la economía social como un "enfoque diferente de la empresa" cuyo motor principal no es la rentabilidad financiera sino los beneficios para toda la sociedad, de modo que las particularidades de la economía social se tomen debidamente en cuenta en la elaboración de los marcos jurídicos.

- Recomendación dirigida a la Comisión y a los Estados miembros para que integren la dimensión "economía social" en la elaboración de las políticas comunitarias y

\footnotetext{
${ }^{6}$ Por RD. 140/1997, de 31 de enero, se modifica parcialmente la estructura orgánica del Ministerio de Trabajo y Asuntos Sociales, y se crea la Dirección General de de Fomento de la Economía Social, asumiendo las funciones en materia de fomento de la economía social que tenía el extinguido Instituto Nacional de Fomento de la Economía Social. Por RD 2288/1998, de 23 de octubre, pasa a denominarse Dirección General de Fomento de la Economía Social y del Fondo Social Europeo, denominación que ha ido variando en el tiempo hasta la actual de DG de Economía Social, del Trabajo Autónomo y de la Responsabilidad Social de las Empresas.

${ }^{7}$ Resolución aprobada el 19 de febrero de 2009 (2008/2250/(INI)), DOUE C76E de 25.03.3010.

${ }^{8}$ Según la resolución que comentamos, la economía social conjuga rentabilidad y solidaridad y desempeña un papel primordial en la economía europea porque permite crear empleos de calidad y refuerza la cohesión social y territorial, la ciudadanía activa, la solidaridad y el desarrollo sostenible.

${ }^{9}$ El estatuto de la sociedad cooperativa europea fue aprobado por Reglamento CE 1435/2003 del Consejo, de 22 de julio de 2003, y completado en lo que respecta a la implicación de los trabajadores en la misma, mediante Directiva 2003/72/CE.
} 
nacionales y en los programas europeos destinados a las empresas en el ámbito de la investigación, la innovación, la financiación, el desarrollo regional y la cooperación al desarrollo, y que apoyen la organización de programas de formación a la economía social para los administradores europeos, nacionales y locales.

Impulsada por esta Resolución del Parlamento Europeo de 2009 y por los trabajos que desde marzo de 2007 venían desarrollándose en torno a la economía social en el seno de la Comisión de Economía y Hacienda del Congreso de los Diputados, se promovió y finalmente se aprobó la Ley de Economía Social de 29 de marzo de 2011.

Dicha ley define la economía social; señala sus principios orientadores; identifica las entidades que forman para de la economía social y crea un catálogo de las mismas en el Ministerio de Trabajo e Inmigración; describe qué debe entenderse por confederaciones intersectoriales de ámbito estatal representativas; reconoce como tarea de interés general la promoción, estímulo y desarrollo de las entidades de la economía social y de sus organizaciones representativas, y señala cuales pueden ser objetivos de las políticas de promoción de la economía social por parte de los poderes públicos; y por último, regula el Consejo para el Fomento de la Economía Social.

La ley define la economía social en su art. 2 como conjunto de actividades económicas y empresariales, que en el ámbito privado llevan a cabo aquellas entidades que, de conformidad con los principios recogidos en el art. 4 persiguen bien el interés colectivo de sus integrantes, bien el interés general económico o social, o ambos. La economía social se define por tanto como una forma de hacer empresa que se caracteriza por sus fines y por determinados principios o pautas de actuación.

Los fines son satisfacer bien el interés colectivo de sus integrantes (finalidad mutualista), bien el interés general económico o social (fin solidario), o ambos.

Los principios orientadores son:

a) Primacía de las personas y del fin social sobre el capital, que se concreta en gestión autónoma y transparente, democrática y participativa, que lleva a priorizar la toma de decisiones más en función de las personas y sus aportaciones de trabajo y servicios 
prestados a la entidad o en función del fin social, que en relación a sus aportaciones al capital social.

b) Aplicación de los resultados obtenidos de la actividad económica principalmente en función del trabajo aportado y servicio o actividad realizada por las socios y socios y, en su caso, al fin social objeto de la entidad.

c) Promoción de la solidaridad interna y con la sociedad que favorezca el compromiso con el desarrollo local, la igualdad de oportunidades entre hombres y mujeres, la cohesión social, la inserción de personas en riesgo de exclusión social, la generación de empleo estable y de calidad, la conciliación de la vida personal, familiar y laboral y la sostenibilidad.

d) Independencia respecto a los poderes públicos.

La ley identifica determinadas formas jurídicas como entidades de economía social, pero sin ánimo exhaustivo, ampliando dicha consideración a aquellas otras entidades cuyas reglas de funcionamiento respondan a los principios reflejados en la ley, y sean incluidas en el catálogo de entidades de economía social que elaborará y actualizará el Ministerio de Trabajo e Inmigración.

\section{EL FOMENTO DE LA ECONOMÍA SOCIAL EN LA CONSTITUCIÓN Y EN LOS ESTATUTOS DE AUTONOMÍA}

La Constitución Española no recoge en su texto ninguna referencia expresa al término “economía social”; no obstante son diversos los preceptos que se señalan para fundamentar su protección. Así, la Ley de Economía Social señala en el apartado II de su exposición de motivos, que resulta de interés destacar el sustrato jurídico en el que se fundamentan las entidades de la economía social que obtiene el más alto rango derivado de los artículos de la Constitución Española. Y señala como principal sustrato jurídico los arts. 1.1, 9.2 y 129.2.

El art. 1.1 describe España como un Estado social y democrático de Derecho, que propugna como valores superiores de su ordenamiento jurídico la libertad, la justicia, la igualdad y el pluralismo político. El art. 9.2 por su parte, ordena a los poderes públicos promover las condiciones para que la libertad y la igualdad del individuo y de los grupos en que se integra sean reales y efectivas; remover los obstáculos que impidan o dificulten su plenitud y facilitar la participación de todos los ciudadanos en la vida política, económica, 
cultural y social. Por último, el art. 129.2 ordena a los poderes públicos promover eficazmente las diversas formas de participación en la empresa y fomentar mediante una legislación adecuada, las sociedades cooperativas. Así mismo, también establecerán los medios que faciliten el acceso de los trabajadores a la propiedad de los medios de producción.

Por el contrario, los Estatutos de Autonomía de las Comunidades Autónomas, tras las reformas llevadas a cabo a partir de 2006 han ido incorporando expresas referencias en sus textos a la economía social. En este sentido, las CCAA de Valencia, Aragón o Castilla y León ${ }^{10}$ asumen en sus Estatutos competencias en materia de fomento de las entidades de economía social; Cataluña ${ }^{11}$ asume competencias exclusivas en materia de fomento y ordenación del sector de la economía social; y Andalucía ${ }^{12}$ añade a todo ello que, serán objeto de atención preferente en las políticas públicas, las entidades de economía social.

\section{LAS INSTITUCIONES PÚBLICAS Y EL FOMENTO DE LA ECONOMÍA SOCIAL}

Todas las Administraciones Públicas tanto del Estado como de las Comunidades Autónomas, han asumido competencias de fomento de la economía social y normalmente estas competencias han sido asignadas a la administración competente en materia de trabajo y asuntos sociales.

En el caso de la Administración del Estado, es la Dirección General de la Economía Social, del Trabajo Autónomo y de la Responsabilidad Social de las Empresas, del Ministerio de Trabajo e Inmigración, quien asume entre otras funciones, el diseño, gestión y control de las ayudas que se concedan a cooperativas, sociedades laborales y otras entidades de economía social, así como a sus asociaciones; o la formación empresarial específica de las empresas y entidades de la economía social.

\footnotetext{
${ }^{10}$ LO 1/2006, de 10 de abril de reforma del Estatuto de Autonomía de la Comunidad Valenciana (art. 80); LO 5/2007, de 20 de abril de reforma del Estatuto de Autonomía de Aragón (art. 71.31) o LO 14/2007, de 30 de noviembre de reforma del Estatuto de Autonomía de Castilla y León (art. 70.1.28 ).

${ }^{11}$ LO 6/2006, de 19 de julio de reforma del Estatuto de Autonomía de Cataluña (arts. 45.5 y 124). En la misma línea, el art. 134 de la propuesta de reforma del Estatuto de Autonomía de Castilla-La Mancha, reconocía a la Comunidad Autónoma competencia exclusiva en materia de "cooperativas y economía social" (BOCCLM $n^{\circ}$ 212 de 31/01/2007). La Iniciativa de Reforma fue retirada posteriormente (BOCG 13.05. 2010).

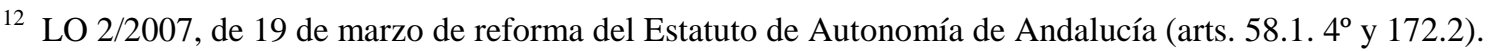


En el ámbito de las Comunidades Autónomas también podemos encontrar Direcciones Generales que tienen por objetivo prioritario el fomento de la economía social. Este es el caso de la DG de Economía Social y Emprendedores, de la Consejería de Innovación, Ciencia y Empresa (Andalucía); la DG de Economía Social de la Consejería de Economía y Empleo (Castilla y León); la DG de Economía Social, del Departamento de Justicia, Empleo y Seguridad Social (País Vasco); la DG de Trabajo, Cooperativismo y Economía Social, de la Consejería de Economía, Hacienda y Empleo (Comunidad Valenciana) o la DG de Comercio, Autónomos y Economía Social de la Consejería de Industria y Empleo (Asturias). En otras Comunidades Autónomas los departamentos especializados en el fomento de la economía social tienen rango de subdirección general ${ }^{13}$; de Servicio ${ }^{14}$ o de Sección ${ }^{15}$.

Al margen de la existencia de departamentos administrativos que se ocupan de elaborar, aplicar y controlar políticas públicas de promoción de la economía social, también podemos encontrar en la Administración española instituciones públicas participadas por agentes de la economía social que tienen funciones relacionadas con el fomento de la economía social.

Algunas de esas instituciones son de ámbito más general, como el Consejo Económico y Social de España en cuya composición se integran cuatro representantes de la economía social $^{16}$. Otras instituciones son en cambio específicas de la economía social, como el Consejo para el Fomento de la Economía Social (CFES).

\footnotetext{
${ }^{13}$ Subdirección General de Cooperativas y Economía Social, integrada en la Dirección General de Relaciones Laborales de la Consejería de Trabajo y Bienestar (Galicia), o la Subdirección de Promoción de la Economía Social del Servicio Canario de Empleo.

${ }^{14}$ Como el Servicio Regional de Empleo, organismo autónomo adscrito a la Consejería de Empleo, Mujer e Inmigración (Comunidad de Madrid), que se ocupa del fomento de la economía social y del trabajo autónomo (Decreto 32/2005), o el Servicio de Registro de Entidades de Economía Social de la DG de Trabajo de la misma Consejería.

${ }^{15}$ Como la Sección Economía Social y Desarrollo Local, del Servicio de Promoción de Empleo perteneciente al Instituto Aragonés de Empleo.

${ }^{16}$ El Consejo Económico y Social, que se regula por la Ley 21/1991, de 17 de julio, es un órgano consultivo del Gobierno en materia socioeconómica y laboral, y una plataforma permanente de diálogo entre el Gobierno y las organizaciones socio-profesionales. Todas las Comunidades Autónomas cuentan con Consejos similares, aunque no en todas ellas tiene representación la economía social. Los Consejos de Baleares, Cataluña, Comunidad Valenciana, Extremadura y Navarra tienen representación de la economía social; Castilla-La Mancha, Castilla y León, Murcia y País Vasco, dan representación a cooperativas y sociedades laborales; en otras Comunidades se prevé su posible presencia como expertos de designación gubernamental (Cantabria y Madrid). Sobre este tema puede verse más ampliamente el Informe para la elaboración de una ley para el fomento de la economía social. Ministerio de Trabajo e Inmigración. Madrid, 2010 pp. 125 ss.
} 
El Consejo para el Fomento de la Economía Social, fue creado por la ley 27/1999 de Cooperativas (Disposición adicional segunda), como órgano asesor y consultivo para las actividades relacionadas con la economía social, y como órgano de colaboración y coordinación del movimiento asociativo y la Administración General del Estado. El CFES está integrado en la Administración General del Estado, a través del Ministerio competente en materia de Trabajo, aunque sin participar en la estructura jerárquica de ésta.

Entre las funciones asignadas a este organismo podemos citar su colaboración en la elaboración de proposiciones sobre cualquier disposición legal o reglamentaria que afecte a entidades de la economía social o informar los programas de desarrollo y fomento de la economía social.

La organización y funcionamiento del CFES fue desarrollado por el Real Decreto 219/2001, de 2 de marzo. En su composición están representados bajo la dirección del Secretario General de Empleo, varios vocales con rango de director general en representación de diversos ministerios; un vocal en representación de cada Comunidad Autónoma y de cada una de las Ciudades de Ceuta y Melilla; un vocal en representación de la asociación de entidades locales más representativa; varios vocales en representación del movimiento asociativo de la economía social de ámbito estatal (cooperativas, sociedades laborales, mutualidades de previsión social, asociaciones sectoriales de las anteriores); y otros vocales designados por el Ministerio de Trabajo entre personas de reconocido prestigio en el ámbito de la economía social ${ }^{17}$.

Instituciones similares al CFES podemos encontrar en el ámbito de las Comunidades Autónomas. Así podemos señalar el Consejo de Promoción de la Economía Social de la Comunidad de Madrid $^{18}$, el Consejo Regional de Economía Social de Castilla-La Mancha ${ }^{19}$ o

\footnotetext{
${ }^{17}$ La ley de economía social da nueva redacción a la regulación del Consejo para el Fomento de la Economía Social aunque respeta en su mayor parte la regulación actual. Merece destacarse no obstante como novedad la incorporación al Consejo de las organizaciones sindicales más representativas, y en sustitución del movimiento asociativo de la economía social: las confederaciones intersectoriales representativas de ámbito estatal y las entidades sectoriales mayoritarias de la economía social que no estén representadas por las citadas confederaciones intersectoriales (art. 9.3).

${ }^{18}$ Regulado por el Decreto 40/2001, de 22 de marzo, y suprimido posteriormente con la Ley 9/2010 de 23 de diciembre, de Medidas fiscales, administrativas y de racionalización del sector público.

${ }^{19}$ Regulado por el art. 143 Ley 20/2002, de 14 de noviembre de Cooperativas, y desarrollado por Decreto $193 / 2005$, de 27 de diciembre.
}

REVESCO No 107 - Primer Cuatrimestre 2012 - ISSN: 1885-8031 - www.ucm.es/info/revesco 
de Castilla y León ${ }^{20}$, el Consejo de la Economía Social y del Cooperativismo de las Illes Balears $^{21}$, o el Consejo Asturiano de la Economía Social ${ }^{22}$. En esta Comunidad Autónoma también es reseñable la Fundación para el Fomento de la Economía Social ${ }^{23}$, entre cuyas funciones está la promoción, divulgación, investigación y asesoramiento de las empresas de economía social.

Todos ellos se configuran como órganos asesores y consultivos para las actividades relacionadas con la economía social, y órgano de colaboración y coordinación del movimiento asociativo, de la administración autonómica y de otros agentes, y en su composición tienen representación tanto la administración autonómica y local, como el movimiento asociativo de la economía social, además de expertos independientes, y en ocasiones, representantes de otros colectivos como sindicatos u organizaciones empresariales.

\section{MEDIDAS DE FOMENTO DE LA “ECONOMÍA SOCIAL” EN LA LEGISLACIÓN ESPAÑOLA}

Un análisis exhaustivo de este tema debería partir de una categorización completa de las diversas políticas públicas existentes, como la realizada por Chaves (2010: 6), que diferencia:

a) Según la distinta atención prestada al sector de la economía social en dichas políticas, entre políticas específicas, políticas generales y políticas excluyentes. Siendo las primeras las dirigidas exclusivamente a este sector social; las segundas se dirigen a cualquier tipo de empresa, y las excluyentes, como su nombre indican son políticas dirigidas al sector privado que excluyen explícita o económicamente a las empresas de la economía social

\footnotetext{
20 Regulado por Decreto 11/2009, de 29 de enero.

${ }^{21}$ La Ley 1/2003 de Cooperativas de las Illes Balears preveía la creación de un órgano asesor, de carácter consultivo y de participación, colaboración y coordinación entre el movimiento cooperativo y la Administración Pública de la Comunidad Autónoma, pero fue el Plan Director de la Economía Social de las Illes Balears (20072008) el que establecía el compromiso de crear el Consejo de la Economía Social de las Illes Balears. El Consejo se crea y regula por Decreto 52/2009, de 7 de agosto.

${ }^{22}$ Regulado en la Ley de Cooperativas del Principado de Asturias 4/2010 de 29 de junio (arts. 201-202) y pendiente de desarrollo.

${ }^{23}$ Esta fundación, constituida en 1989 está integrada por representantes de diversas organizaciones: Principado de Asturias, Unión General de Trabajadores, Comisiones Obreras, Unión de Cooperativas Agrarias Asturianas y Agrupación de Sociedades Asturianas de Trabajo Asociado
} 
b) Según que las políticas se dirijan a la economía social en su conjunto o a alguna de sus familias, diferencia entre políticas transversales, dirigidas a la globalidad del sector de la economía social, y políticas sectoriales, las dirigidas a subcampos de la economía social (cooperativas, instituciones sin fines lucrativos, etc.).

c) Según los instrumentos desplegados en las políticas dirigidas a la economía social, distingue entre políticas de oferta, que se dirigen a la estructura de las empresas de la economía social, y políticas de demanda, cuyo objeto es incidir en el volumen de actividad económica de las empresas de economía social, promoviendo su contratación, por ejemplo, a través de cláusulas sociales en la contratación de las administraciones públicas.

d) Las políticas de oferta pueden a su vez articularse a dos niveles: como políticas institucionales, dirigidas a institucionalizar la economía social, reconociendo su identidad diferenciada, su capacidad para actuar en cualquier sector de actividad económica o su condición de co-protagonista en el proceso de elaboración y aplicación de las diferentes políticas públicas; y como políticas de difusión, formación e investigación.

Esta completa categorización nos da una idea de los diversos enfoques que podemos utilizar al analizar el fomento de la economía social, pero nuestro objetivo no es tan ambicioso, y va a limitarse a analizar aquellas normas que directa y expresamente aluden a la economía social, en el ordenamiento jurídico español, como beneficiaria de ayudas y subvenciones. Para este análisis vamos a diferenciar las medidas de apoyo, en atención al poder público del que emana la norma.

\subsection{El fomento de la economía social en la legislación del Estado}

El Estado convoca anualmente subvenciones a las actividades de promoción de la economía social, y para sufragar los gastos de funcionamiento de las asociaciones de cooperativas, de sociedades laborales, de empresas de inserción, de trabajadores autónomos y otros entes representativos de la economía social de ámbito estatal. El Ministerio de Trabajo e Inmigración, a través de la Dirección General de Economía social, Trabajo Autónomo y Responsabilidad Social de las Empresas, tiene atribuida la función de impulsar y ejecutar, en el ámbito de la Administración General del Estado, la actuación política en el sector de la economía social (art. 15 Real Decreto 1129/2008 de 4 de julio). Las medidas adoptadas para 
el fomento de la economía social, se encuentran reguladas por la Orden TIN/3440/2009 de 16 de diciembre y su convocatoria para 2011 tuvo lugar con la Orden TIN/3297/2010, de 15 de diciembre.

Las subvenciones que se convocan tienen una doble finalidad, por una parte, contribuir a la financiación de los gastos derivados de la realización de actividades de promoción de la economía social; y por otra, contribuir a la financiación parcial de los gastos generales de las asociaciones de entidades de economía social mencionadas.

Las actividades que pueden ser objeto de promoción han de tener ámbito estatal y consistir en: actividades de formación tendentes a iniciar, perfeccionar y cualificar en el conocimiento de la economía social; organización de congresos, seminarios, jornadas, etc.; elaboración de estudios, trabajos de documentación, análisis e investigación; edición de folletos, publicaciones y otras actuaciones análogas, o campañas publicitarias para la promoción de la economía social.

Constituyen prioridades temáticas a la hora de valorar las solicitudes de subvención las siguientes: Legislación sobre economía social, cooperativas y sociedades laborales; Sociedad Cooperativa Europea; empresas de inserción; I+D+i en las empresas de economía social; difusión de las formas empresariales y sociales de la economía social y medidas para su fomento.

Otras medidas que merecen destacarse son las ayudas al fomento del empleo y a la mejora de la competitividad de cooperativas y sociedades laborales; y las ayudas a la integración cooperativa.

El Estado es competente para regular los programas de fomento del empleo en cooperativas y sociedades laborales, por lo que le corresponde regular el destino, condiciones y tramitación de las subvenciones y ayudas, dejando a salvo la potestad autonómica de autoorganización de los servicios. La Orden TAS/3501/2005, de 7 de noviembre establece las bases reguladoras para la concesión de subvenciones para el fomento del empleo y mejora de la competitividad en las cooperativas y sociedades laborales. 
Las actuaciones subvencionables son: la incorporación de socios trabajadores o socios de trabajo a cooperativas y sociedades laborales; la prestación de asistencia técnica; la realización de actividades de formación, difusión y fomento de la economía social vinculadas directamente al fomento del empleo, y la realización de inversiones que contribuyan a la creación, consolidación o mejora de la competitividad de cooperativas y sociedades laborales. Estas últimas medidas, al estar contempladas en el Programa Operativo del FEDER "Mejora de la Competitividad y Desarrollo del Tejido Productivo", son cofinanciadas por este fondo. Las demás medidas son cofinanciadas con cargo al Fondo Social Europeo, al estar contempladas en los Programas Operativos de este Fondo "Iniciativa Empresarial y Formación Contínua".

Por otra parte, el Ministerio de Medio Ambiente, Medio Rural y Marítimo destina ayudas al fomento de la integración de entidades agrarias de la economía social. La Orden APA/180/2008, de 22 de marzo ${ }^{24}$ establece las bases reguladoras de estas subvenciones que define como destinadas al fomento de la integración cooperativa de ámbito estatal, pero cuyos beneficiarios no son solo cooperativas del sector agrario, sino también sociedades agrarias de transformación y cualquier entidad económica siempre que más del $50 \%$ de su capital social pertenezca a alguna de las anteriores entidades.

El objetivo de esta norma es capacitar al sector empresarial agrícola para poder hacer frente al desafío de la competitividad. Para ello se fomenta el asociacionismo agrario creando estructuras empresariales de mayor dimensión que faciliten la cooperación interterritorial y la economía en red. También se pretende con esta orden, consolidar el tejido social del medio rural mediante el relevo generacional y sobre todo, mediante una mayor participación de la mujer en la toma de decisiones de la empresa agraria y en los puestos directivos.

Los gastos subvencionables son los generados por la integración y gastos de gestión anual derivados de inversiones materiales e inmateriales, alquiler de locales, o gastos de personal directamente relacionado con el proyecto, colaboraciones externas (asistencia técnica, consultoría, etc.).

\footnotetext{
${ }^{24}$ Esta Orden fue modificada por Orden ARM/2759/2008 de 19 de septiembre. La Resolución de 2 de abril de 2009, convoca estas ayudas destinadas al fomento de la integración cooperativa para el ejercicio 2009.
} 


\subsection{El fomento de la economía social en Andalucía}

Al tratar del fomento de la economía social en Andalucía debe hacerse referencia necesariamente, a su previsión en el Estatuto de Autonomía como objeto de atención preferente de las políticas públicas (art. 172.2), y a los Pactos por la Economía Social suscritos hasta el momento: I Pacto Andaluz (2002) y II Pacto (2006).

El II Pacto Andaluz por la Economía Social, vigente en este momento, fue suscrito el 23 de octubre de 2006 entre la Junta de Andalucía, la Confederación de entidades para la Economía Social de Andalucía (CEPES-Andalucía), Comisiones Obreras de Andalucía y la Unión General de Trabajadores de Andalucía.

Con este pacto, los firmantes tienen como objetivo contribuir al desarrollo económico y social de Andalucía mediante el fomento y consolidación de la economía social como sector estratégico creador de empresas y empleo de calidad.

El pacto se concreta en cinco objetivos de fomento y sus respectivas líneas estratégicas de actuación y medidas aplicables: 1. Fomento de la creación de empresas de economía social, así como impulso a la cooperación y asociación de las mismas como fórmula para su mejor dimensionamiento ${ }^{25}$. 2. Desarrollo y consolidación de los factores intangibles de competitividad de las empresas de economía social ${ }^{26}$. 3. Fomento del empleo y la formación, así como de las condiciones de trabajo y de las relaciones laborales en las empresas de economía social ${ }^{27}$. 4. Generación, transferencia y utilización de la innovación y fomento de las Tecnologías de la Información y Comunicación ${ }^{28}$. 5. Impulso de la presencia de empresas

\footnotetext{
${ }^{25}$ Líneas estratégicas que comprende: Ampliación y consolidación de empresas de economía social; fomento de la cooperación entre las empresas de economía social; fomento del asociacionismo y de la concertación asociativa en el sector agroalimentario; impulso y apoyo a la vertebración y desarrollo del movimiento asociativo de la economía social, y fomento del conocimiento de la relevancia y alcance de la economía social.

${ }^{26}$ Líneas estratégicas que comprende: Acciones que potencien la responsabilidad social derivada de la propia naturaleza de las empresas de economía social; promoción de sistemas integrados de calidad y excelencia empresarial, y fomento del diseño industrial.

${ }^{27}$ Líneas estratégicas que comprende: Fomento del empleo y singularmente del autoempleo asociado y mejora de la formación de los trabajadores y socios en las empresas y organizaciones de la economía social.

${ }^{28}$ Líneas estratégicas que comprende: Promover una cultura de innovación de la tecnología de economía social; apoyo a la modernización y actualización de la tecnología utilizada por las empresas de economía social; fomentar la generación y transferencia de la innovación en las empresas de economía social, y fomento de la utilización de las Tecnologías de la Información y comunicación.
} 
de economía social en los nuevos yacimientos de empleo relacionados con los servicios de proximidad.

En aplicación de este Pacto, de sus objetivos y estrategias, anualmente, la Junta de Andalucía viene convocando medidas de apoyo a la economía social. Así, la Orden de 29 de junio de 2009 establece las bases reguladoras de un programa de apoyo a la innovación y al desarrollo de la economía social, y efectúa su convocatoria para los ejercicios 2009 a 2013. Este programa se estructura en tres líneas estratégicas, a través de las cuales se concretan medidas específicas de fomento: a) Difusión, promoción e innovación de la economía social $^{29}$; b) Desarrollo profesional ${ }^{30}$, y c) Desarrollo asociativo ${ }^{31}$.

\subsection{El fomento de la economía social en Asturias}

El fomento de la economía social en Asturias constituye una de las actuaciones establecidas en el Acuerdo para la Competitividad, el Empleo y el Bienestar en Asturias (ACEBA), firmado por el Gobierno del Principado de Asturias y los agentes sociales; concretamente se incluye en el Programa de Fomento y Consolidación del Autoempleo Colectivo: Economía Social (sub-apartado 5.2.2 del Apartado II Promoción Económica).

Los objetivos de este Programa son: fomentar el empleo a través del autoempleo colectivo; facilitar a las empresas de economía social el acceso al asesoramiento técnico necesario para paliar las carencias técnicas internas que puedan dificultar su desarrollo; fomentar el conocimiento de la economía social y el asociacionismo, favoreciendo la consolidación de las iniciativas económicas procuradas por las empresas de economía social, cooperativas y sociedades laborales así como el acercamiento de las empresas de economía social a las tecnologías de la información y la comunicación (ESTIC).

\footnotetext{
${ }^{29}$ Las acciones que son objeto de fomento son: Jornadas, seminarios y encuentros para difundir y promover la economía social; publicaciones; difusión en medios de comunicación; investigación, estudios, asesoramiento, ejecución y desarrollo de planes de competitividad, o los Premios Arco Iris del Cooperativismo.

${ }^{30}$ Se fomenta a través de medidas de formación profesional para la economía social y apoyo a la incorporación de socias y socios en cooperativas y sociedades laborales.

31 Se fomentan medidas que impulsen la vertebración de la economía social y consoliden sus estructuras representativas; que fomenten el desarrollo de organizaciones sectoriales de economía social; y acciones de fomento del cooperativismo que acuerde el Consejo Andaluz de Cooperación, especialmente, de difusión, educación y formación sobre los principios del cooperativismo y promoción de programas de desarrollo y fomento de las cooperativas y otras fórmulas de economía social.
} 
Por Resolución de 5 de noviembre de 2009 de la Consejería de Industria y Empleo se aprueban las bases y normas reguladoras para la concesión de subvenciones recogidas en el Programa de Fomento y Consolidación del Autoempleo colectivo: empresas de economía social, previstas en el Acuerdo para la Consolidación, el Empleo y el Bienestar en Asturias; y por Resolución de la misma fecha se aprueba la respectiva convocatoria pública de subvenciones para los ejercicios 2010 y 2011.

Las ayudas que ofrece esta convocatoria son: ayudas a cooperativas y sociedades laborales para la incorporación de desempleados; subvenciones directas a la inversión y la bonificación de intereses de los préstamos destinados a financiar estas inversiones; programa de asesoramiento técnico; programa para fomentar el conocimiento de la economía social y fomentar el asociacionismo; consolidación de iniciativas económicas procuradas por las empresas de economía social; programa ESTIC y programa de ayudas a los perceptores de la prestación por desempleo en su modalidad de pago único.

\subsection{El fomento de la economía social en las Illes Balears}

La Comunidad de las Illes Balears disponía hasta hace poco de un Pla Director de Foment de l'Economia Social (2007-2008), que establecía los principales elementos orientadores de la política de fomento de este sector en la Comunidad, y que servía a su vez de guía para establecer las diferentes estrategias y acciones en esta materia. Los objetivos de este Plan eran: fomentar la creación de empleo por medio de la creación de organizaciones de economía social; consolidar las entidades ya existentes, especialmente las cooperativas agrarias, fomentando procesos de fusión y de colaboración entre cooperativas, encaminados hacia el incremento de la dimensión empresarial y social, y fortalecer las estructuras de apoyo sectorial y territorial existentes en esta materia ${ }^{32}$.

La Dirección General de Responsabilidad Social Corporativa de la Consellería de Turismo y Trabajo es la competente en materia de fomento, formación y registros públicos de economía social.

\footnotetext{
32 Tras la constitución del Consejo de la Economía Social y del Cooperativismo en 2009, se está trabajando en la elaboración de un Pla Estratègic per a l’Economia Social de les Illes Balears. Este plan extiende su ámbito a las cooperativas, sociedades laborales, empresas de inserción, centros especiales de empleo, iniciativas de comercio justo o intercambio solidario y, a cualquier otra empresa, cualquiera que sea su forma jurídica, cuyos estatutos asuman los principios de gestión propios de la economía social.
} 
La Orden de 4 de mayo de 2005, modificada por Orden de 16 de julio de 2008 fija las bases reguladoras de las subvenciones en materia de trabajo, y entre las materias subvencionables señala las actividades de formación, difusión y fomento en el ámbito de la economía social.

El fomento de la economía social en esta Comunidad se dirige fundamentalmente a la formación, al fomento del autoempleo y al apoyo a las entidades asociativas de la economía social $^{33}$.

\subsection{El fomento de la economía social en Canarias}

El Servicio Canario de Empleo convoca subvenciones dirigidas a fomentar la creación y consolidación de empresas calificadas como I+D, empresas de economía social y empresas de inserción; y subvenciones para la realización de actividades de difusión, fomento y formación de la economía social.

En el primer caso son acciones subvencionables ${ }^{34}:$ los gastos para la puesta en marcha de cooperativas con socios trabajadores o de trabajo o de sociedades laborales; las inversiones en activo fijo que resulten necesarias para la creación y consolidación de cooperativas con socios trabajadores o de trabajo y sociedades laborales; y la incorporación de socios trabajadores o de trabajo a cooperativas y sociedades laborales.

También son subvencionables la realización de actividades de difusión y fomento de la economía social, vinculadas directamente al fomento del empleo; y la realización de

\footnotetext{
${ }^{33}$ Véase al respecto las Resoluciones de 14 de diciembre de 2010 por las que se aprueban: la convocatoria para financiar acciones formativas a realizar por parte de entidades asociativas de la economía social y del trabajo autónomo, para la promoción y fomento de la auto-ocupación de mujeres y hombres; la convocatoria para conceder ayudas públicas a las entidades asociativas de las cooperativas, sociedades laborales y de iniciativa de la inserción social, para la formación, cofinanciada en un 50\% por los Fondos Sociales Europeos por medio del Programa Operativo FSE de las Illes Balears 2007-2013; y la Resolución de 13 de diciembre de 2010 por la que se aprueba la convocatoria para conceder ayudas públicas para dar apoyo a las entidades asociativas de cooperativas y sociedades laborales en el periodo comprendido entre el 1 de noviembre de 2009 y 30 de abril de 2010.

${ }^{34}$ Véase Resolución de 22 de abril de 2010, por la que se establece la convocatoria para el año 2010 de concesión de subvenciones dirigidas a fomentar la creación y consolidación de empresas calificadas como I+E, de Empresas de Economía Social y de Empresas de Inserción, en el marco del Plan Canarias Emplea, cofinanciadas por el Fondo Social Europeo.
} 
actividades de formación de economía social, siempre que estén vinculadas al fomento del empleo y destinadas a iniciar, perfeccionar y cualificar en el conocimiento del cooperativismo y de la economía social a desempleados, socios de cooperativas y sociedades laborales, y a otras personas interesadas en la creación o mejor funcionamiento de las empresas de economía social, con especial atención a los colectivos con dificultades de acceso al mercado.

\subsection{El fomento de la economía social en Cantabria}

En Cantabria, la Consejería de Empleo y Bienestar Social concede subvenciones destinadas al fomento del empleo y mejora de la competitividad y consolidación de las cooperativas y sociedades laborales, así como a promover las actividades de formación, fomento y difusión de la economía social y a sufragar los gastos de organización interna y funcionamiento de las asociaciones de cooperativas, de sociedades laborales, trabajadores autónomos y otros entes representativos de la economía social establecidas y que ejerzan su actividad habitualmente en la Comunidad de Cantabria ${ }^{35}$.

Dicha convocatoria comprende diversos programas de ayudas:

Programa I: Incorporación de socios trabajadores o socios de trabajo a cooperativas y sociedades laborales.

Programa II: Inversiones en inmovilizado material o inmaterial que contribuyan a la creación, consolidación o mejora de la competitividad de cooperativas y sociedades laborales, en su doble modalidad de subvenciones directas y bonificaciones de intereses de los préstamos, incluidos los microcréditos, destinados a la realización de aquellas inversiones.

Programa III: Asistencia técnica. Prestación de asistencia técnica a cooperativas y sociedades laborales.

Programa IV: Actividades de formación, difusión y fomento de la economía social, vinculadas directamente al fomento del empleo.

Programa V: Apoyo a entidades representativas de la economía social y el autoempleo. Ayudas destinadas a sufragar los gastos de organización interna y funcionamiento de

\footnotetext{
${ }^{35}$ Véase Orden EMP/38/2010, de 19 de marzo, por la que se establecen las bases reguladoras y se aprueba la convocatoria para el año 2010 de subvenciones destinadas al fomento del empleo y mejora de la competitividad en las cooperativas y sociedades laborales y a financiar gastos de organización interna y funcionamiento de las asociaciones de cooperativas, de sociedades laborales, trabajadores autónomos y otros entes representativos de la economía social.
} 
asociaciones de cooperativas y de sociedades laborales, de las asociaciones de trabajadores autónomos y otros entes representativos de la economía social.

\subsection{El fomento de la economía social en Castilla-La Mancha}

La Comunidad de Castilla-La Mancha, a través del Decreto 142/2009, de 20 de septiembre, regula subvenciones para promover la creación, el desarrollo y la competitividad de las empresas de economía social.

Dicho Decreto tiene por objeto establecer las bases y convocar subvenciones a cooperativas, sociedades laborales y a las asociaciones y federaciones de estas entidades con el fin de favorecer su creación, desarrollo y competitividad.

Las líneas de subvención que se establecen son:

1. Subvenciones para la promoción y el empleo: subvenciones a la constitución de la entidad; para la generación de puestos de trabajo; para la incorporación de socios y socias trabajadoras en cooperativas y sociedades laborales; a la formación o para la contratación de personal especializado.

2. Subvenciones a la inversión: en su modalidad general o dirigidas al fomento de la creación de cooperativas y sociedades laborales formadas por mujeres.

3. Subvenciones para la mejora de la competitividad: subvenciones a la innovación y el desarrollo tecnológico; promoción de la calidad, del diseño, planes estratégicos de empresa y asistencia técnica.

4. Subvenciones para el fomento de la comercialización e internacionalización: promoción del comercio exterior, asistencia a ferias y convenciones comerciales interiores, y cooperación inter-empresarial.

\subsection{El fomento de la economía social en Castilla y León}

La Comunidad de Castilla y León convoca subvenciones para la incorporación de socios trabajadores o de trabajo en cooperativas y sociedades laborales, y el fomento y difusión de la economía social, vinculadas directamente al fomento del empleo (Orden EYE/1772/2010, de 22 de diciembre). 
Estas medidas son consecuencia del desarrollo de la Orden TAS/3501/2005 de 7 de noviembre que establece las bases reguladoras par la concesión de subvenciones para el fomento del empleo y mejora de la competitividad en las cooperativas y sociedades laborales, adecuada a las peculiaridades organizativas de esta Comunidad, mediante la Orden EYE/404/2009, de 19 de febrero; y del Plan Estratégico de Subvenciones 2009-2011 aprobado por Orden de 26 enero 2009, que incluye entre las líneas de subvención las relativas a la incorporación de socios trabajadores o de trabajo en cooperativas y sociedades laborales, y al fomento y difusión de la economía social vinculadas directamente al fomento del empleo.

La Orden de 22 de diciembre de 2010 tiene por objeto convocar subvenciones dirigidas a fomentar la incorporación de socios trabajadores o de trabajo en cooperativas y sociedades laborales, sean personas desempleadas o trabajadores con contrato de trabajo de carácter temporal en la misma cooperativa o sociedad laboral en la que se integra como socio; y el fomento y difusión de la economía social vinculadas directamente al fomento del empleo.

\subsection{El fomento de la economía social en Cataluña}

Cataluña asume en su Estatuto de Autonomía la tarea de estimular las iniciativas de la economía social (art. 45.5) y el fomento de este sector (art. 124.3), y su Departamento de Trabajo es el competente en materia de relaciones laborales, ocupación, economía social, cooperativas y auto-empresa, y formación profesional y continua (Decreto 421/2006 de 28 de noviembre). Estas competencias fueron asignadas a la DG de Economía Cooperativa, Social y de Auto-ocupación, que en 2007 cambió su denominación por DG de Economía Cooperativa y Creación de empresas (Decreto 199/2007, de 10 de septiembre).

Estos cambios estructurales en la Administración catalana pueden ser la causa que justifique la generalización en los últimos años de la expresión economía cooperativa, que se identifica con cooperativas y sociedades laborales, en detrimento de economía social.

Entre las principales medidas de fomento de la economía social podemos citar las dirigidas al desarrollo de las empresas de economía cooperativa y al fomento, promoción y divulgación 
de las cooperativas y sociedades laborales ${ }^{36}$; y las dirigidas a financiar planes de formación específicos para la economía social ${ }^{37}$.

Son líneas subvencionables para la Orden TRE/142/2010: la incorporación de socios o socios trabajadores/as o socios o socias de trabajo en cooperativas y sociedades laborales; los proyectos empresariales de cooperativas y sociedades laborales de nueva creación; los proyectos empresariales de fortalecimiento e intercooperación destinada a cooperativas y sociedades laborales; las entidades representativas de la economía cooperativa y la promoción, difusión e investigación de la economía cooperativa.

\subsection{El fomento de la economía social en Extremadura}

Extremadura cuenta con un Plan de Fomento y Calidad del Empleo (2008-2011) suscrito por la Junta de Extremadura, la Unión General de Trabajadores, Comisiones Obreras, la Confederación Regional Empresarial Extremeña y la Federación de Municipios y Provincias de Extremadura.

Dicho Plan establece una serie de prioridades, estrategias y medidas dirigidas a favorecer el acceso al empleo y la integración laboral de todas las personas, sobre todo de quienes más dificultades tienen, mujeres, jóvenes, personas en situación de discapacidad y colectivos con especiales dificultades de inserción en el mercado de trabajo.

Una de las prioridades del Plan es el Fomento del Empleo y del Autoempleo, entre cuyos objetivos está: 5.3 Impulsar la economía social, el empleo autónomo y el tercer sector. Son medidas a desarrollar para la consecución de este objetivo, las acciones integradas de empleo en economía social y tercer sector (5.3.3.), y la transformación de las entidades sin ánimo de lucro en entidades de economía social (5.3.4).

\footnotetext{
${ }^{36}$ Orden TRE/142/2010, de 8 de marzo, por la que se establecen las bases reguladoras de las subvenciones para el desarrollo de las empresas de economía cooperativa y para fomentar, promocionar y divulgar las cooperativas y sociedades laborales. Modificada por Orden TRE/364/2010, de 21 de julio.

${ }^{37}$ Resolución EMO/1195/2011, de 5 de mayo, por la que se aprueba la convocatoria de 2011 para la concesión de subvenciones públicas para la financiación de planes de formación de oferta de carácter intersectorial, específicos para la economía social, y de carácter sectorial destinados a trabajadores/as prioritariamente empleados/as, que promueve el Consorcio para la Formación Continua de Cataluña.
}

REVESCO No 107 - Primer Cuatrimestre 2012 - ISSN: 1885-8031 - www.ucm.es/info/revesco 
Como consecuencia del desarrollo de este Plan, la Junta de Extremadura viene convocando ayudas principalmente para el fomento del empleo en el ámbito de la economía social, y para apoyar a las entidades asociativas de la economía social.

El Decreto 126/2008, de 20 de junio regula el programa de ayudas para el fomento del empleo en el ámbito de la economía social. Este programa se desglosa en dos tipos de actuaciones. Por una parte se subvenciona la creación de empleo estable, sea mediante la incorporación de desempleados como socios trabajadores o de trabajo a sociedades cooperativas y sociedades laborales, como la transformación de contratos temporales de sus trabajadores en contratos indefinidos, al tiempo que adquieren la condición de socios trabajadores. Por otra, se da apoyo técnico a sociedades cooperativas, sociedades laborales y sus entidades asociativas, subvencionándoles la contratación de personal técnico y directivo.

El Decreto 199/2009, de 28 de agosto ${ }^{38}$ aprueba las bases reguladoras de subvenciones destinadas a apoyar a entidades asociativas de la economía social y el autoempleo de la C.A. de Extremadura y aprueba la convocatoria de dichas subvenciones para 2009. Este Decreto concede ayudas a entidades asociativas de sociedades cooperativas, de sociedades laborales, así como de trabajadores autónomos, y ayudas a entidades asociativas de la economía social.

\subsection{El fomento de la economía social en Galicia}

El fomento de la economía social en Galicia se refleja fundamentalmente en la Orden de 14 de junio de 2010 por la que se establecen las bases reguladoras de los programas de fomento del empleo en empresas de economía social, y de promoción del cooperativismo, y se procede a su convocatoria para el año 2010.

Esta Orden, como dice en su exposición de motivos, pretende reforzar una visión integral de apoyo a la economía social en la C.A de Galicia, y por ello agrupa los programas de promoción, divulgación y difusión del cooperativismo, y el programa de fomento del empleo en cooperativas y sociedades laborales, que se adecua a la Orden del MTAS 3501/2005, de 7 de noviembre.

\footnotetext{
${ }^{38}$ Modificado por Decreto 151/2010, de 2 de julio.
} 
El objeto de la Orden es fijar las bases reguladoras y la convocatoria de las ayudas y subvenciones con la finalidad de promover la incorporación de personas desempleadas a las entidades de economía social, apoyar el desarrollo de proyectos de creación y modernización de este tipo de empresas, mediante una mejora de su competitividad, así como la promoción de cooperativas a través de los siguientes programas: Fomento del empleo en cooperativas y sociedades laborales; Mejora de la competitividad en cooperativas y sociedades laborales; Impulso de proyectos empresariales cooperativos y asistencia técnica; Fomento del acceso a la condición de socio/a trabajador/a y Actividades de promoción del cooperativismo.

Los programas de promoción del cooperativismo y economía social establecen ayudas para el impulso de proyectos empresariales cooperativos, incluso en la fase previa a su constitución formal, potenciando singularmente los procesos de asesoramiento y acompañamiento de las nuevas iniciativas; fomentan específicamente el acceso a la condición de socios y socias trabajadores/as para incentivar la plena integración en la empresa cooperativa y contemplan ayudas para la realización de actividades de promoción del cooperativismo.

El programa de fomento de empleo en cooperativas y sociedades laborales, por su parte, establece un conjunto de ayudas orientadas a facilitar la incorporación de las personas desempleadas, como socios y socias trabajadores/as o de trabajo en las cooperativas o sociedades laborales gallegas, al considerar las distintas fórmulas de autoempleo colectivo como medidas eficaces para la generación de empleo, movilización de recursos, corrección de desequilibrios comarcales y fijación de mano de obra productiva, estableciendo vínculos de interés mutuo entre la población y su propio territorio. Asimismo, se pretende, mediante incentivos para la financiación de las inversiones en inmovilizado material e inmaterial, aumentar la competitividad de estas empresas con el objeto último de mantener su empleo.

\subsection{El fomento de la economía social en La Rioja}

La Comunidad de la Rioja mediante la Orden de 22 de marzo de 2005 estableció las bases reguladoras y el procedimiento de concesión de ayudas destinadas al fomento de las cooperativas y sociedades laborales, adaptando con ello la Orden TAS/3501/2005 al ámbito de esta Comunidad. 
Aquella Orden fue sustituida por la Orden de 30 de marzo de 2007, de la Consejería de Hacienda y Empleo, por la que se establecen las bases reguladoras para la concesión de ayudas al programa de fomento de la Economía Social en la Comunidad Autónoma de la Rioja.

Esta Orden (cuya aplicación se extiende a 2009 por Resolución n ${ }^{\circ} 265$ de 17 de agosto de 2009), establece tres programas de ayuda:

a) Apoyo a Cooperativas y Sociedades Laborales. Dentro de este capítulo son subvencionables: la incorporación de socios trabajadores o de trabajo en empresas de economía social; gastos notariales y registrales, asistencia técnica, subvenciones financieras, y por la realización de inversiones en activos fijos que contribuyan a la creación o mantenimiento de puestos de trabajo en este tipo de empresas.

b) Apoyo a la contratación de gerentes o especialistas en economía social. Se subvenciona la contratación indefinida por parte de cooperativas y sociedades laborales de directores o gerentes, valorándose positivamente el grado de especialización en economía social de dichos profesionales.

c) Incentivos a la conciliación de la vida familiar y laboral de la mujer que se incorpore como socia trabajadora a Cooperativas y Sociedades Laborales. Se subvenciona la incorporación de mujeres como socias a una empresa de economía social y que tengan a su cargo hijos menores de tres años o familiares dependientes hasta el segundo grado inclusive por consanguinidad o afinidad que necesiten asistencia de terceras personas. También pueden acogerse a estas ayudas las varones que ejerciendo la tutela legal, siempre que se trate de hogares monoparentales, se incorporen como socios a una empresa de economía social.

\subsection{El fomento de la economía social en Madrid}

La Comunidad de Madrid tiene competencias en el ámbito de la Economía Social y el Trabajo Autónomo desde 1996 y las desarrolla a través del Servicio Regional de Empleo. Las medidas de fomento son principalmente dos. Por una parte, se conceden ayudas para el fomento del empleo y mejora de la competitividad de cooperativas y sociedades laborales, y por otra, se conceden ayudas para sufragar los gastos de funcionamiento de las entidades asociativas. 
La Orden 3935/2009, de 31 de diciembre por la que se convocan ayudas para el fomento del empleo y mejora de la competitividad en las cooperativas y sociedades laborales en el ámbito de la Comunidad de Madrid para el año 2010, adapta a esta Comunidad las bases reguladoras establecidas en la Orden TAS/3501/2005, de 7 de noviembre.

Las actuaciones subvencionables por esta Orden son: a) Incorporación de desempleados como socios trabajadores o socios de trabajo a cooperativas y sociedades laborales; b) Realización de inversiones que contribuyan a la creación, consolidación o mejora de la competitividad de cooperativas y sociedades laborales; c) Prestación de asistencia técnica, y d) Realización de actividades de formación, difusión y fomento de la economía social vinculadas directamente al fomento del empleo.

La Orden 3520/2005, de 20 de septiembre establece las bases que regulan la concesión de ayudas y subvenciones públicas para sufragar los gastos de funcionamiento de las entidades asociativas de cooperativas, de sociedades laborales y de trabajadores autónomos en el ámbito de la Comunidad de Madrid.

Según esta Orden, son subvencionables el coste correspondiente a los salarios de los trabajadores de estas entidades asociativas, y determinados gastos de infraestructura y mantenimiento. Los beneficiarios de estas ayudas pueden ser las entidades asociativas de cooperativas y sociedades laborales, las entidades asociativas de trabajadores autónomos de carácter intersectorial y otros entes representativos de la economía social.

La Orden 2049/2010 de 11 de junio, convoca estas ayudas para el año 2010 y modifica la anterior Orden 3520/2005. Una de las novedades introducidas por esta Orden es que extiende la condición de beneficiarios de estas subvenciones a las entidades asociativas de empresas de inserción, y por otra parte, limita las ayudas a los entes representativos de la economía social, al exigir que integren asociaciones de cooperativas y de sociedades laborales.

\subsection{El fomento de la economía social en Murcia}

Murcia cuenta desde el 24 de marzo de 2009 con un I Plan Regional de Economía Social con vigencia para tres años. Dicho Plan fue suscrito por el Gobierno Regional, la 
Unión de Cooperativas de Trabajo Asociado, la Asociación de Empresas de Economía Social, la Federación de Cooperativas Agrarias, la Unión de Cooperativas de Enseñanza y la Federación de Sociedades Agrarias Cooperativas, de la Región de Murcia.

Los objetivos de este Plan son:

1. Fomentar la creación de Empresas de Economía Social, su crecimiento, así como impulsar la cooperación y asociación de las mismas como fórmula para su expansión.

2. Desarrollar, mejorar y consolidar todos los factores de competitividad de las empresas de economía social.

3. Fomentar el empleo y la formación, así como las condiciones de trabajo y las relaciones laborales en las empresas de economía social.

4. Impulsar la presencia de empresas de economía social en todos los sectores y en especial en los nuevos yacimientos de empleo, especialmente los relacionados con los servicios de proximidad.

5. Impulsar la intercooperación entre las entidades asociadas a cada organización.

Para la realización de los anteriores objetivos, el Plan establece diversas actuaciones a realizar: Acciones de fomento e incentivación; de formación e investigación; divulgativas y de sensibilización y de coordinación institucional y social.

En desarrollo de estos objetivos, la Orden de 24 de febrero de 2010 de la Consejería de Educación, Formación y Empleo, regula las bases y convoca subvenciones para Programas de Fomento de la Economía Social para 2010.

Los programas subvencionables son:

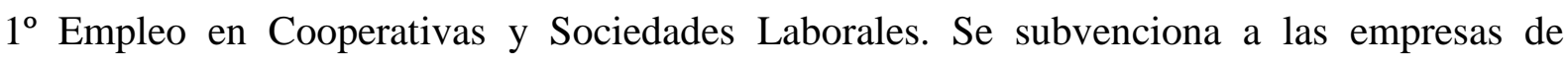
economía social que incorporen como socios trabajadores a determinadas personas.

$2^{\circ}$ Aportaciones en Economía Social. Se subvencionará a las empresas de economía social por cada socio trabajador que realice aportaciones dinerarias que incrementen el capital social escriturado.

$3^{\circ}$ Reestructuración Financiera. Con este programa se subvencionan préstamos necesarios para llevar a cabo un plan de reestructuración financiera de empresas y organizaciones empresariales de economía social con domicilio social y fiscal en la Región de Murcia. 
$4^{\text {o }}$ Asistencia Técnica en Economía Social. Permite subvencionar: estudios previos para la obtención de financiación; estudios y análisis sobre áreas de gestión empresarial; auditorías e informes económicos; asistencia en la selección de personal; estudios de viabilidad económico-financiera, organización, comercialización, estudios de mercado, etc.; diseños de catálogos comerciales, páginas web, etc.

$5^{\circ}$ Difusión y Fomento de la Economía Social: campañas de difusión en medios de comunicación, edición de publicaciones, congresos, jornadas, participación en ferias, certámenes, etc.

$6^{\circ}$ Organizaciones Empresariales de la Economía Social. Su objetivo es fomentar y consolidar las estructuras representativas o asociativas de la economía social.

$7^{\circ}$ Inversiones en Economía Social. Se conceden ayudas para realizar inversiones en activos fijos materiales nuevos, o de segunda mano.

$8^{\circ}$ Orientación Profesional en Economía Social. Se promueven las actividades de orientación profesional que fomenten directamente la colocación en el mercado laboral a los desempleados.

$9^{\circ}$ Centros de Asesoramiento en Economía Social. Están destinados a la promoción e impulso de iniciativas que generen empleo y riqueza en la Región, y presten asesoramiento a las sociedades cooperativas y a las sociedades laborales.

$10^{\circ}$ Economía Social en las Universidades Públicas. Este programa tiene por objetivo subvencionar a las universidades públicas de la Región de Murcia para que lleven a cabo actividades de investigación, docencia y difusión sobre temas relacionados con las características propias de la economía social y principalmente con las sociedades cooperativas y sociedades laborales.

\subsection{El fomento de la economía social en Navarra}

Navarra adaptó la Orden TAS 3501/2005 que establece las bases reguladoras para la concesión de subvenciones para el fomento del empleo y la mejora de la competitividad en las cooperativas y sociedades laborales, mediante la Resolución 4180/2008 de 18 de diciembre, que aprobaba a su vez la convocatoria de ayudas.

Según esta Resolución, son objeto de subvención: la incorporación de socios trabajadores o socios de trabajo a cooperativas y sociedades laborales; la realización de inversiones que contribuyan a la creación, consolidación o mejora de la competitividad de 
cooperativas y sociedades laborales; prestación de asistencia técnica; realización de actividades de formación, difusión y fomento de la economía social vinculadas directamente al fomento del empleo.

Al margen de estos programas de ayuda, el Servicio Navarro de Empleo ha adoptado otras medidas de apoyo a la economía social como son ayudas a la sucesión empresarial en empresas de economía social y ayudas a la conversión de empresas en empresas de economía social.

La Resolución 1739/2007, de 4 de junio, aprueba la convocatoria de ayudas a la sucesión empresarial en empresas de economía social. Se trata de ayudas dirigidas a personas físicas que se incorporen como socios-trabajadores en sociedades laborales y cooperativas de trabajo asociado que lleven al menos, un año en funcionamiento. Su finalidad es favorecer la entrada de nuevos socios para posibilitar la continuidad de las propias empresas.

La Resolución 2069/2008, de 20 de junio, aprueba la convocatoria de ayudas a la conversión de empresas en empresas de economía social. Su objeto es establecer un régimen de concesión de subvenciones para cofinanciar la incorporación de trabajadores como socios trabajadores o de trabajo en empresas de economía social cuando la empresa a la que pertenecen adquiera la forma jurídica de sociedad laboral o cooperativa.

\subsection{El fomento de la economía social en País Vasco}

La Comunidad Autónoma del País Vasco, a través de la Consejería de Empleo y Asuntos Sociales, emplea diversas medidas de fomento de la economía social, medidas que desglosa en diversas disposiciones, siendo las más relevantes las siguientes.

Orden de 17 de junio de 2009. Esta orden establece ayudas dirigidas a la consolidación de estructuras asociativas de empresas de economía social. Los posibles beneficiarios de estas ayudas son estructuras con personalidad jurídica propia, que asocien, para la representación y defensa de sus intereses, a sociedades laborales y cooperativas de trabajo asociado, o a cooperativas distintas del trabajo asociado y entidades asociativas de carácter confederal. Las ayudas se destinan a financiar gastos de estructura para el mantenimiento y consolidación de las entidades asociativas. Considera gastos de estructura, los gastos de personal al servicio de 
la entidad asociativa; los gastos de funcionamiento y los gastos externos relacionados con la actividad ordinaria de la estructura, tales como informes jurídicos, auditorías, defensa, etc.

Orden de 7 de julio de 2010 por la que se establecen ayudas para la formación en Economía Social. Estas ayudas se dirigen a la realización de: actividades formativas, de investigación y divulgación acerca de los aspectos específicos de la economía social.

Son actividades formativas subvencionables las destinadas a la formación específica en economía social societario-empresarial, destinadas a iniciar, perfeccionar y cualificar el conocimiento del cooperativismo o de las sociedades laborales; y las acciones formativas sobre economía social en el ámbito universitario y pre-universitario.

Entre las acciones de investigación subvencionables se cita la elaboración de materiales didácticos destinados a la formación de personas socias y trabajadoras, personal directivo o no; actividades de investigación en economía social; edición de publicaciones, etc.

Por último, son actividades de difusión subvencionables, aquellas cuyo objetivo sea dar a conocer o divulgar entre la población en general o a colectivos específicos la economía social, mediante: la organización de congresos, seminarios, simposios, jornadas, etc.; y la organización de actividades para atender a grupos nacionales o internacionales interesados en conocer la experiencia cooperativa del País Vasco.

Orden de 7 de julio de 2010 por la que se establecen ayudas para la intercooperación empresarial en la economía social. Los gastos subvencionables pueden ser diversos: gastos externos de consultoría derivados de estudios de intercooperación; gastos externos de consultoría necesarios para la elaboración y la formalización de acuerdos y la creación de empresas o estructuras de intercooperación empresarial; gastos por la prestación de asistencia técnica y formativa realizada por las entidades representativas de cooperativas y sociedades laborales de Euskadi; gastos netos externos ocasionados por la fusión en la que participen entidades de economía social; gastos ocasionados por la incorporación de una sociedad de economía social en empresas o estructuras de intercooperación ya constituidas; gastos ocasionados a las entidades representativas de cooperativas y sociedades laborales de Euskadi por su participación en Organizaciones representativas de economía social de carácter internacional, y gastos para la asistencia técnica y la formación necesaria respecto a la 
realización de proyectos que tengan como objeto la creación de grupos empresariales de economía social en el ámbito internacional.

Orden de 7 de julio de 2010 por la que se regulan las ayudas para la asistencia técnica en las empresas de economía social. Se consideran acciones de asistencia técnica, la elaboración e implantación del Plan de Gestión Anual y del Plan Estratégico; el asesoramiento externo en la gestión a las personas administradoras de pequeñas empresas de la economía social; el asesoramiento específico en gestión comercial de pequeñas cooperativas y sociedades laborales; la elaboración de valoraciones de los puestos de trabajo en pequeñas empresas de economía social, el diseño e implantación en pequeñas empresas de economía social de sistemas de información y comunicación; etc.

Orden de 7 de julio de 2010 por la que se regulan las ayudas para la incorporación de personas socias a empresas de economía social. Las ayudas tienen por objeto que personas desempleadas se incorporen a empresas con forma jurídica de sociedad cooperativa o laboral, en calidad de personas socias trabajadoras o de trabajo de duración indefinida; y que titulares de explotaciones agrarias, ganaderas, forestales y mixtas, se incorporen como personas socias a cooperativas agrarias.

Orden de 21 de julio de 2010 por la que se articulan las ayudas para emprender en economía social. El objeto de estas ayudas puede ser: la realización de actividades de promoción directamente relacionadas con la constitución de una empresa de economía social; la constitución de empresas de economía social; actividades específicas de información y difusión de la cultura emprendedora, exclusivamente en economía social; la realización del estudio de viabilidad económica y financiera de sociedades anónimas y limitada con un nivel creciente de pérdidas y el proceso de constitución de cooperativas de trabajo asociado o sociedades laborales por parte de las personas trabajadoras de las empresas en las que se ha realizado previamente el estudio de viabilidad citado.

Orden de 1 de septiembre de 2010 por la que se establecen las ayudas para la participación de personas trabajadoras en empresas de economía social. Con esta orden se subvenciona fundamentalmente la incorporación como personas socias trabajadoras o socias de trabajo de las personas trabajadoras no socias con contrato laboral indefinido por cuenta ajena, en activo en la entidad de economía social; pero también, el diseño e implantación en 
las empresas de economía social de instrumentos que favorezcan la participación financiera de nuevas personas socias trabajadoras posibilitando el relevo generacional; los gastos externos necesarios de evaluación y consultoría para la elaboración e implantación de herramientas específicas de responsabilidad social empresarial que incluyan los principios de la economía social.

\subsection{El fomento de la economía social en Valencia}

La Generalitat Valenciana, a través de su Consellería de Economía, Hacienda y Empleo, concede ayudas destinadas a la promoción, fomento y difusión de la economía social. La Orden 24/2010, de 4 de junio aprueba las bases reguladoras de estas ayudas y convoca su concesión para 2010.

Las entidades beneficiarias de estas ayudas pueden ser las entidades asociativas de cooperativas y sociedades laborales, las federaciones de mutualidades de previsión social, fundaciones públicas que tengan entre sus fines el fomento o promoción de las entidades de economía social, y los centros o institutos universitarios especializados en materias propias de la economía social.

Las actividad subvencionables son: los gastos generales y de funcionamiento de las entidades asociativas de las cooperativas, sociedades laborales y mutualidades de previsión social; las actividades de formación, fomento y difusión de la economía social, la inversión en inmuebles o equipamiento, y la implementación o mantenimiento de redes especializadas de información en materias propias o relacionadas con las empresas de economía social.

También merece destacarse la Orden 30/2010, de 27 de julio de la misma Consellería $^{39}$, por la que se aprueban las bases reguladoras para la concesión de ayudas destinadas al fomento de las cooperativas y sociedades laborales.

Las actuaciones que esta Orden subvenciona son: la incorporación, con carácter indefinido, como socios trabajadores o de trabajo en cooperativas y sociedades laborales,

\footnotetext{
39 Orden que adapta la correlativa Orden TAS/3501/2005 que establece las bases para la concesión de subvenciones para el fomento del empleo y mejora de la competitividad de las cooperativas y sociedades laborales
}

REVESCO No 107 - Primer Cuatrimestre 2012 - ISSN: 1885-8031 - www.ucm.es/info/revesco 
preexistentes o de nueva constitución, de desempleados y de trabajadores, con contrato de trabajo de carácter temporal, en la misma cooperativa o sociedad laboral en la que se integran como socios; la realización de inversiones en activos fijos e inmovilizado, y la prestación de asistencia técnica.

Por último, merece destacarse la Orden 36/2010 de 3 de septiembre, por la que se aprueban las bases reguladoras para la concesión de subvenciones a trabajadores y socios de cooperativas y sociedades laborales, destinadas a facilitar su acceso a la condición de socios trabajadores o de trabajo de las empresas en que presten sus servicios, o a incrementar su participación financiera en ellas, y se convocan las citadas ayudas para 2010. El objeto de estas subvenciones es el gasto necesario hecho por el trabajador para acceder a la condición de socio, y el gasto necesario hecho por el trabajador ya socio, para adquirir una participación análoga a la de los restantes socios.

\section{EL FOMENTO DE LA ECONOMÍA SOCIAL EN LA LEY DE ECONOMÍA SOCIAL}

El fomento de la economía social como objetivo prioritario de la ley de economía social, sufrió una notable evolución. Desde el Informe de expertos sobre la elaboración de una ley, que denomina, "de fomento de la economía social", y dedica tres artículos ${ }^{40}$ y numerosas medidas a esta tarea; pasando por el anteproyecto de ley de economía social, aprobado en junio de 2010 por el Consejo de Ministros, donde el fomento quedaba reducido a una declaración genérica de promoción, estímulo y desarrollo de la economía social, hasta la ley finalmente aprobada, que ha venido ampliando a lo largo de su tramitación los objetivos que deben tener las políticas públicas de promoción de la economía social.

Así, la ley de economía social reconoce como tarea de interés general, la promoción, estímulo y desarrollo de las entidades de la economía social y de sus organizaciones representativas; y detalla diversos objetivos que deben integrarse en las políticas de promoción de la economía social de los poderes públicos.

\footnotetext{
${ }^{40}$ Art. 10 "Políticas de fomento de la economía social", art. 11 "Difusión, formación e investigación de la economía social", y art. 12 "Apoyo financiero y crediticio a las iniciativas de creación y desarrollo de empresas y entidades de la economía social".
} 
Son objetivos de las políticas de promoción de la economía social para los poderes públicos, según esta ley:

a) Remover los obstáculos que impidan el inicio y desarrollo de una actividad económica de las entidades de economía social. Para ello se prestará especial atención a la simplificación de trámites administrativos para la creación de entidades de la economía social.

b) Facilitar las diversas iniciativas de economía social.

c) Promover los principios y valores de la economía social.

d) Promocionar la formación y readaptación profesional en el ámbito de las entidades de la economía social.

e) Facilitar el acceso a los procesos de innovación tecnológica y organizativa a los emprendedores de las entidades de economía social.

f) Crear un entorno que fomente el desarrollo de las iniciativas económicas y sociales en el marco de la economía social.

g) Involucrar a las entidades de economía social en las políticas activas de empleo, especialmente a favor de los sectores más afectados por el desempleo, mujeres, jóvenes y parados de larga duración.

h) Introducir referencias a la economía social en los planes de estudio de las diferentes etapas educativas.

i) Fomentar el desarrollo de la economía social en áreas como el desarrollo rural, la dependencia y la integración social.

La competencia para impulsar la promoción, difusión y formación de la economía social se encomienda al Ministerio de Trabajo, sin perjuicio de las facultades de otros departamentos ministeriales en relación con la actividad económica, empresarial y social que desarrollen las entidades de la economía social. A estos fines, la Ley incorpora un programa a 6 meses de impulso de la economía social con medidas concretas: revisar la normativa para eliminar las trabas injustificadas en su actividad económica; actualizar la ley de sociedades laborales, y revisar la normativa sobre subvenciones para simplificar sus procedimientos en favor de las entidades que realizan acción social (DA $7^{\mathrm{a}}$ ).

Se reconoce también la competencia de las CCAA en el fomento de la economía social, y se ordena a la Administración del Estado que impulse mecanismos de cooperación y 
colaboración con ellas, con el fin entre otros de compensar y equilibrar los desajustes territoriales ${ }^{41}$.

\section{CONCLUSIONES}

El fomento de la economía social a través de la integración de esta dimensión en las políticas públicas, debería ser, un objetivo de los Estados que integran la Unión Europea, según la Resolución del Parlamento Europeo sobre la Economía Social (2009).

España integra la dimensión "economía social” en sus políticas públicas desde la Orden de 21 de febrero de 1986, que estableció determinadas ayudas para la creación y mantenimiento de cooperativas y sociedades laborales, así como para el desarrollo y la difusión del cooperativismo y la economía social; a través del Programa “Apoyo al empleo en Cooperativas y Sociedades Laborales" ${ }^{\text {. }}$. Este programa pasa a denominarse, a partir de la Orden de 29 de diciembre de 1998, "Desarrollo de la Economía Social".

En desarrollo de este Programa, el Estado articula diversas líneas de fomento, principalmente a través de dos órdenes. La Orden TIN/3440/2009, de 16 de diciembre que establece las bases reguladoras de la concesión de subvenciones a las actividades de promoción de la economía social y para sufragar los gastos de funcionamiento de los entes representativos de la economía social en el ámbito estatal; y la Orden TAS/3501/2005, de 7 de noviembre, que establece las bases reguladoras para la concesión de subvenciones para el fomento del empleo y mejora de la competitividad en las cooperativas y sociedades laborales.

Para el desarrollo de este Programa, actualmente denominado "Desarrollo de la Economía Social y de la Responsabilidad Social de las Empresas" existe una consignación presupuestaria en los Presupuestos Generales del Estado, que es objeto de transferencia

\footnotetext{
41 Desajustes que se producen por la diferente atención que las Comunidades Autónomas dan en sus presupuestos al fomento de la economía social, y sobre todo, porque desde 2007 muchas Comunidades Autónomas han dejado de ser Objetivo 1 para la Unión Europea (Véase Recomendación $6^{\circ}$ del Informe de la Subcomisión para el fomento de la economía social (BOCG del Congreso de los Diputados de 2 de junio de 2011).

${ }^{42}$ Este programa tenía como finalidad, según establece su art. 1 “conceder ayudas económicas para la creación o conservación de puestos de trabajo mediante la constitución, ampliación del número de socios, o mantenimiento de cooperativas o sociedades laborales, así como subvencionar la asistencia técnica y formación que mejore la gestión de las mismas y/o la promoción cooperativa y comunitaria que contribuya al desarrollo de la economía social".
} 
directa del Estado a las Comunidades Autónomas que tienen asumidas competencias en materia de gestión de dichas ayudas (a excepción del País Vasco y Navarra). Estos fondos son generalmente incrementados con nuevos ingresos procedentes de la Unión Europea (FSE y FEDER).

Como consecuencia de esta estructura presupuestaria, las políticas públicas de fomento de las Comunidades Autónomas suelen coincidir, en sus objetivos y medidas adoptadas, con las del Estado.

Las medidas de fomento de la economía social que están presentes en todas las políticas públicas analizadas son: subvenciones a las actividades de promoción, formación, investigación y difusión de la economía social; y subvenciones de los gastos generales de funcionamiento de las asociaciones de entidades de la economía social. Y en relación con las cooperativas y sociedades laborales: ayudas para, la incorporación de socios de trabajo o socios trabajadores; la prestación de asistencia técnica; la realización de actividades de formación, difusión y fomento de la economía social vinculadas al fomento del empleo, o para inversiones que contribuyan a la creación, consolidación o mejora de la competencia de estas entidades.

No obstante, como hemos visto, en ocasiones las Comunidades Autónomas adoptan medidas particulares (promover el uso de las nuevas tecnologías de la información y comunicación entre las entidades de la economía social; la integración e interoperación entre entidades de la economía social; conciliación de la vida familiar y laboral de los socios de estas entidades; transformación en entidades de la economía social, de las empresas en crisis o de las entidades sin ánimo de lucro, etc.)

A la vista de este panorama, puede afirmarse que en España, si bien se ha generalizado el fomento de la economía social, el grado de implicación de las políticas públicas en dicho fomento, es dispar y dependiente de cada Comunidad Autónoma ${ }^{43}$.

\footnotetext{
${ }^{43}$ Compartimos por tanto la conclusión a la que llega el Informe para la elaboración de una Ley de fomento de la economía social, 2010 p. 114.
}

REVESCO No 107 - Primer Cuatrimestre 2012 - ISSN: 1885-8031 - www.ucm.es/info/revesco 
En cuanto al sentido con que se emplea el término "economía social" en las diversas normas analizadas, todas ellas coinciden en identificar como entidades de economía social las cooperativas, sociedades laborales y asociaciones representativas de éstas.

En alguna ocasión, se extiende el concepto de economía social a las mutualidades de previsión social ${ }^{44}$, y otras parece afectar también a las empresas de inserción, o incluso, a las entidades representativas de los trabajadores autónomos ${ }^{45}$. En todo caso, se limita el concepto de economía social a entidades cuya regulación o promoción corresponde a la administración pública competente en materia de empleo.

En la mayor parte de las ocasiones se hace referencia al fomento de la economía social pero no se especifica qué debe entenderse por economía social. Por ello se agradece que el legislador estatal haya asumido la tarea de definir qué debe entenderse por ésta en la reciente ley de economía social.

Por último, y en relación con el tratamiento del fomento de la economía social en la ley que comentamos, celebramos el desarrollo que el mismo experimentó en su tramitación parlamentaria, pero debemos recordar que el catálogo de objetivos y medidas a adoptar que menciona, es meramente enunciativo, y por tanto, los poderes públicos pueden ampliarlos, y en esta tarea debería tenerse en cuenta la relación de medidas de fomento que contemplaba la propuesta de ley de fomento de la economía social elaborada por el grupo de expertos.

También debe subrayarse que con la nueva ley el ámbito de la economía social se amplía más allá de las cooperativas y sociedades laborales, incluyendo entidades cuya regulación y fomento no son competencia del Ministerio de Trabajo (fundaciones, asociaciones, sociedades agrarias de transformación o cofradías de pescadores). Sin embargo, la ley al asignar la competencia en la promoción de la economía social sigue atribuyendo a este Ministerio la tarea de impulsar la economía social "en su ámbito", sin perjuicio de las facultades de otros departamentos ministeriales en relación con la actividad económica

\footnotetext{
${ }^{44}$ Como entidades con representación en el Consejo para el Fomento de la Economía Social, o como beneficiarias de las ayudas a la promoción de la economía social y entidades representativas de la economía social, en la Comunidad Valenciana.

${ }^{45}$ Este es el caso en la Orden estatal 3440/2009 y en la normativa de las Comunidades de Baleares, Canarias, Cantabria o Madrid.
} 
empresarial y social que desarrollen las entidades de economía social para el cumplimiento de su objeto social.

Si la economía social se concibe como un sector, con fines comunes y merecedora por ello de una política de fomento, su promoción debería comprender a todas las entidades que la integran y no sólo -como hasta ahora- a aquellas cuyo fomento sea competencia del Ministerio de Trabajo o departamentos competentes en materia de trabajo. Quizá la solución debería de pasar por la creación de un organismo interministerial dedicado a la promoción de la economía social como existe en otros países ${ }^{46}$, similar al antiguo Instituto de Fomento de la Economía Social (INFES).

\section{BIBLIOGRAFIA}

AAVV. Informe para la elaboración de una ley de fomento de la economía social. Madrid, Ed. Ministerio de Trabajo e Inmigración, 2010.

ALFONSO SÁNCHEZ, R. "La legislación española sobre cooperativas y sociedades laborales: ¿una respuesta adecuada a las necesidades del sector?” CIRIEC. Revista Jurídica, 2009, no 20, pp. 9 ss.

ALFONSO SÁNCHEZ, R. "Algunas consideraciones en torno a la propuesta de Ley "marco" de economía social". REVESCO, 2010, nº 102, pp. 7-23

CHAVES, R. "El análisis de la Economía Social en las Políticas Públicas. Visión de conjunto". En: La economía social en las políticas públicas en España, Chaves (Dir.) Valencia, Ed. CIRIEC, 2010.

FAJARDO GARCÍA, I.G. "La economía social en las leyes" Rev. CIRIEC, 2009, nº 66, pp. 5 y ss.

MARTÍ-COSTA, M. (Dir.) Políticas públicas de promoción de cooperativas en España. Una visión comparada entre Comunidades Autónomas. Ed. Institut de Govern i Politiques Públiques, 2010.

SÁNCHEZ PACHÓN, L.A. "La delimitación de las entidades y organizaciones de economía social en la próxima ley reguladora del sector” Rev. CIRIEC, 2009, n 66, pp. 61 y ss.

\footnotetext{
${ }^{46}$ Entre otros: Reino Unido (Social Enterprise Unit y Third Charity and Third Sector Finance Unit), Francia (Délégation à l'économie sociale), Bélgica (Secrétariat d'Etat au Développement Durable et à l'Economie Sociale) o Portugal (Cooperativa António Sérgio para a Economia Social -CASES). Véase: La economía social en la Unión Europea. Comité Económico y Social Europeo, 2008 pp. 79 -82.
}

REVESCO No 107 - Primer Cuatrimestre 2012 - ISSN: 1885-8031 - www.ucm.es/info/revesco 
SÁNCHEZ PACHÓN, L.A. "El reconocimiento de la economía social y de sus agentes en el proyecto de Ley de Economía social” Noticias del CIDEC, 2010, nº 54, pp. 53-58.

VALDÉS DAL-RE, F. "La representación institucional de la economía social: una aproximación desde el derecho vigente y desde el derecho propuesto" Rev. CIRIEC, 2009 $\mathrm{n}^{\circ} 66, \mathrm{pp} .37$ ss. 